\title{
Editorial - Challenging Building Blocks: The coherence of cosmological evolution, life, consciousness, morality and building the 21st century
}

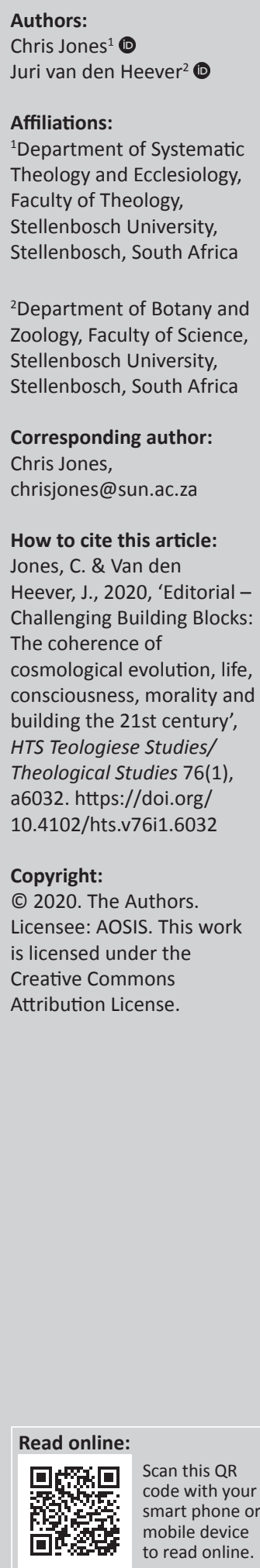

Scan this $Q R$ code with your smart phone or mobile device to read online.

The collection of articles reflect academically on five selected challenging building blocks of our past, present and future (as living beings), preceded by a brief introductory review of the building blocks of the cosmos. According to us, these are the fundamental issues that many people on our planet grapple with. Hence the articles aim to add academic value, locally and globally. From a mainly qualitative methodological perspective, these scholarly articles demonstrate that reflection on these challenging issues requires analytical thinking and critical people who in an existentially and emancipatory way can help us to better understand these building blocks of our past, present and future. The co-authors who represent different academic disciplines and research backgrounds, present in the respective articles their research systematically, intersectionally and constructivistically, based on profound theoretical analysis and reasoning. The articles challenge certain conventional borders with insight and expertise. The contributors are all deeply committed to the value and validity of science and ethical practice. Its target audience is international scholars, peers, researchers and educators with an interest in the fields covered in this collection of articles. We can confirm that all the articles are based on original research and that no part of this collection was plagiarised from another publication, or published elsewhere.

\section{Acknowledgements}

\section{Competing interests}

The authors declare that they have no financial or personal relationships that may have inappropriately influenced them in writing this editorial. 